Article

\title{
Development of Sustainable Integrated Design Framework for Stream Restoration
}

\author{
Kidoo Park ${ }^{1, *(1)}$ and Kil Seong Lee ${ }^{2, *}$ \\ 1 Institute of Engineering Research, Seoul National University, 1 Gwanak-ro, Gwanak-gu, Seoul 08826, Korea \\ 2 Department of Civil and Environmental Engineering, Seoul National University, 1 Gwanak-ro, Gwanak-gu, \\ Seoul 08826, Korea \\ * Correspondence: hydrol88@snu.ac.kr (K.P.); kilselee@snu.ac.kr (K.S.L.); Tel.: +82-2-880-8270 (K.P. \& K.S.L.)
}

Received: 19 December 2018; Accepted: 23 January 2019; Published: 28 January 2019

Abstract: This study analyzed the elements of previously published stream restoration guidelines by clarifying the definition of stream restoration classified for various purposes. The purpose of this study was to establish a sustainable integrated design framework for stream restoration that supplemented the limited scope of application and the resulting problems. Stream restoration procedures were established using the method of securing water resources applied with the integrated watershed management in order to effectively and feasibly recover the modified stream, to resolve the water shortage problem, and to effectively restore the ecosystem due to climate change. An 11-step stream restoration procedure was established in three phases including the pre-restoration design phase, the restoration design phase, and the detailed design phase. Furthermore, the three stages were classified into hydrologic and hydraulic plan, geomorphic and sediment transport plan, and ecological and environmental plan depending on the direction of stream restoration, and the procedure for stream restoration was proposed to prevent river restoration from being biased toward a specific goal. An integrated design framework for stream restoration could be established by allowing the proposed stream restoration design procedures (e.g., three phases and three plans) and the elements to be carried out using numerical models for an effective design in establishing river restoration plans. Lastly, it was possible to quantify the problems of existing stream restoration by applying this stream restoration framework to the existing river restoration project and guideline report. As a result, the existing stream restoration project could be used as base data that could provide directions to supplement the weaknesses of the existing stream restoration project and provide directions for the new river restoration projects in the future.

Keywords: integrated watershed management; 11-step stream restoration procedure; pre-restoration design phase; restoration design phase; detailed design phase; hydrologic and hydraulic plan; geomorphic and sediment transport plan; ecological and environmental plan

\section{Introduction}

Until recently, Korea's projects for channel adjustments or channel modification have been mainly emphasized for flood control and water supply, as it has been a critical issue of protecting human life from heavy floods and severe droughts for the past three decades. Eventually, urban stream and artificial stream lost their original functions and shapes of natural streams. In a typical urban stream, it was common to align streams for rapid discharge of flooding, to construct sports facilities in order to utilize waterfront usage, and to build roads and parking lots with respect to the utilization of floodplain in an urban stream. In the end, rapid increases of an impervious area due to urban development and decreases of underground water levels caused stream flow depletion in the urban 
stream. The stream flow shortage and the depletion had a negative effect on the ecosystem since the ecological habitat and self-purification were weakened [1].

In order to improve the functioning of these negative streams, many urban streams have been restored over the past 20 years, from straight channels covered with concrete to natural corridors close to their original appearance. The problems and the lessons learned from various river restoration projects can be categorized as follows: hydrologic and hydraulic restoration, ecological restoration, and environmental restoration. Hydrologic restoration is a typical method for improving the water circulation system of the entire basin by applying the Integrated Watershed Method (IWM) [2]. Thus, hydrologic restoration plans establish structural measures for the entire basin instead of planning river corridors and channels, and the IWM is far from the actual stream restoration. However, structural measures, such as the IWM, must be considered in advance in carrying out the restoration of streams to ensure water quantity in the streams suffering from severe water shortages [1]. Hydraulic restoration is an important factor in rapid release of flood and sediment, and it is highlighted in most urban stream areas. However, in the case of the urban stream, the environmental and ecological aspects are largely ignored [3]. In the case of ecological restoration, it is important to improve the ecosystem environment to restore the aquatic ecosystem. However, in order to restore the hydrologic system, it is necessary to secure the minimum discharge to maintain the aquatic ecosystem. In addition, securing the amount of water demand, through effective water resource management, was essential for the restoration of ecological habitat [4]. On the other hand, in situations where the flow rate assurance is very limited, instream structures using hydraulic dynamic properties can be installed to restore the ecological habitat despite insufficient flow rates [5,6]. An environmental restoration is a very difficult work than others. Environmental restoration is impossible without considering structural measures of hydrologic aspects of IWM [1,2]. Typical restoration cases that highlight waterfront functions of rivers are the two streams in Seoul, Korea. Although the project of the Yangjaecheon and the Cheonggyecheon (e.g., examples of stream restoration in Korea) by the Seoul Metropolitan Government were recognized as a starting point of the stream restoration project in Korea, the purpose of the stream restorations is to only improve the stream environment to provide amenity and the space for leisure time for the citizens [3]. The functions of flood management and water resource utilization for the purpose of stream restoration were not properly considered, which resulted in severe flooding and instream flow depletion [1,7]. In another case of actual restoration, stream restoration was aimed to improve the river waterfront but only the landscape-oriented stream restoration was carried out rather than the engineering considerations of ecological and flood control [8]. Therefore, as mentioned above, the stream restoration considering particular function or biased stream restoration causes a variety of problems. Since hydrologic and environmental aspects are all interconnected, it is essential to establish a systematic and integrated stream restoration system [9]. Lack of concern for conservation of the ecosystem and preservation of the pristine water system caused the negative effects on most of the stream restoration, such as flow changes to the physical ecosystem in river [10] and environmental change to water quality and aquatic habitat [11]. Despite growing interest in integrated restoration, few cases of restoration met all the objectives of ecological, environmental, hydraulic, and hydrologic restoration [12,13].

Therefore, in carrying out the stream restoration project, it is necessary to take into account the three major functions of the stream: flood control, water supply, and ecological management and water quality management. It takes a lot of efforts to develop practical guidelines to satisfy all aspects. It is difficult to find notable achievements and perfect examples of stream restoration projects, or to find general application guidelines that take into account the river's geological, hydrological, hydraulic, ecological, and environmental systems. However, for urban streams, not only did the interest in ecological and environmental streams of streams increase, but flood management was still important [6]. The restoration of the natural topography and ecology of stream is the result of complex and systematic efforts initiated by the improvement of natural or human-induced disturbances and the appropriate recognition of ecological functions. It requires an accurate understanding of the structure 
and functions of the river corridor ecosystem and the physical, chemical, and biological processes that form them [14].

This demand and trend led to the publication of a wide range of guidelines on the river restoration worldwide. A systematic design methodology of the United States [15] was developed to design stream restoration involving channel reconstruction and the methodology included the use of hydraulic geometry relationships, analytical determination of stable channel dimensions, and a sediment transport assessment. Ecological restoration of the aquatic ecosystem began to be emphasized and the ecological stream restoration design approach was evaluated by analyzing its effects of changing flow regimes using the Instream Flow Incremental Methodology (IFIM) process [16]. Design guideline on river restoration was developed including stream restoration plan, analysis of corridor condition, restoration design, and restoration implementation, monitoring and management [17]. A systematic hydraulic design methodology was introduced to hydraulic engineers [9] and the design process was a more challenging example when the urban project reach was unstable due to straightening, channelization, or changing hydrologic or sediment inflow conditions. Spatial and chronological steps of the rehabilitation planning procedure (i.e., 12 steps stream rehabilitation procedure) are presented [18]. The catchment management plans integrated all competing uses of the stream related to their cultural and social significance, recreational value, economic value, and ecological values. A rehabilitation manual for Australian Streams [18] was suggested and the technical manual of restoration planning and activities provided a more detailed framework for stream restoration [19]. The reconstruction of the floodplains [20] suggested on the basis of the natural dynamics of the river on seasonal and yearly fluctuations of river water levels. The method helped to create a landscape with more variation and gradients, a higher river-related biodiversity, and enough space to develop sustainable populations. The urban stream repair manual [21] was concentrated on practices to enhance the appearance, stability, structure, or function of urban streams and three broad approaches were presented to urban stream clean-ups, simple repairs, and more sophisticated comprehensive repair applications. The basic concepts and techniques of urban watershed restoration [22] was introduced to evaluate subwatershed restoration potentials such as storm water retrofits, stream restoration, riparian management, discharge prevention, pervious area restoration, pollution source control, and municipal practices. In addition, the restoration practice, as the application of structural or non-structural techniques in urban sub watersheds, improves stream health, as measured by improvements in physical, hydrological, chemical, ecological, or social indicators [22]. A methodology of the river restoration [23] was proposed through three design categories, such as unnatural rigid design, semi-natural form design, and natural procedure design, according to fluvial geomorphology. The representative Korean guideline $[24,25]$ for the stream restoration was suggested as an integrated manual of stream restoration and the guideline included how to determine restoration reaches, which sets the restoration objectives and determines the restoration type considering ecological, water quality, water quantity, and riverscape. Many guidance reports on the elements of the detailed design process have been prepared, but they were missing or too outlined for links and combinations between the design processes. However, in designing an actual urban stream, it is imperative to present the procedures for each stage of the design and to supply guidelines on the utilization of the software for calculating stream restoration.

The purpose of this study is to present not only the step-by-step procedures for stream restoration, but also to provide the sequence and links of each procedure by designing steps as a sustainable integrated design framework. This study presented a sustainable integrated stream restoration method consistent with all the three functions of stream such as flood control, water supply, and environmental preservation. Thus, this procedure was not only non-biased to particular functions, but also proposed the use of numerical models for an effective stream restoration design. This stream restoration method can be established from the initial stages by implementing the effective establishment of a water resource system considered through the IWM in order to ensure water quantity and improve water quality due to climate change. Since water shortages will be expected due to future climate 
change, the proposed stream restoration process can determine whether to accept structural measures using the IWM. In the case of ecological restoration for the streams that have been destroyed by channel adjustment and modification, the ecological and eco-friendly restoration plan proposed by this study was developed to include the effective procedure of the aquatic ecosystem. In addition, in contrast to the previous cases of stream restoration, which considered only the stream ecology and environmental aspects, a new proposed stream restoration plan was established in which flood control was sufficiently considered to cope with severe flooding. Therefore, this study presented the applicable stream restoration procedures for urban streams incorporating flood control, water supply, and ecological and environmental preservation and compares new procedures to restoration elements presented in the previous stream restoration guidelines report. The new proposed stream restoration design method, as the sustainable integrated design framework, was implemented with a systematic consideration of Hydrologic and Hydraulic $(\mathrm{H} \& \mathrm{H})$ plan, Geomorphic and Sediment transport (G\&S) plan, and the Ecological and Environmental (E\&E) plan. Lastly, the elements of the stream restoration design framework proposed in this study were compared with an existing guideline report and a case study to identify weaknesses in existing stream restoration guidelines and problems in the actual stream restoration from an integrated design perspective.

\section{Definition of Stream Restoration}

Restoration is a comprehensive effort that begins by recognizing nature or human-induced disturbances that are damaging the structure and functions of the ecosystem or preventing its recovery to a sustainable condition. Thus, the biological values of restoration have been emphasized as a very important factor and have provided good measures of the general health of a stream system [18]. Since stream systems rely on a certain level of disturbance by flooding, erosion, and variable water quality, to maintain their diversity. On the contrary, it is not necessary to emphasize the absolute stability in rehabilitation [26]. Nevertheless, the first and most critical step in implementing restoration is to halt disturbance activities causing degradation or preventing recovery of the ecosystem [27]. Restoration actions may range from passive approaches that involve removal or attenuation of chronic disturbance activities to active restoration, intervention, and installation of measures to repair damages to the structure of stream corridors. It can be achieved by helping stream managers restore the physical characteristics of streams, including water quantity and quality, as close to their original ecosystem condition as possible. Therefore, it was necessary to define a generally applicable stream restoration that may include this concept of diverse stream restoration. Stream restorations were defined in three categories, as shown in Figure 1.

\subsection{Restoration}

The restoration (Figure 1) is ideally defined as achieving five objectives [28]: to restore the natural range of water quality, to restore natural sediment and flow regime including the seasonal fluctuations, as well as the annual to decadal pattern of floods, to restore natural channel geometry and stability, to restore natural riparian plant community, and to restore native aquatic plants and animals. It is important to acknowledge that stream restoration will seldom be possible. It is often impossible to establish what its original condition was. Such a restoration would mean modifying the physical and biological characteristics of the reach including the channel form and biological communities so that they replicate the original state. In a few cases, it may only be possible if the entire stream networks and catchments were restored because of the connections between the stream and the catchment. However, it will almost never be possible. 


\subsection{Rehabilitation}

Although a complete restoration of the original ecosystem may not be possible, the most important aspects of the stream environment can be improved and can resemble the original ecosystem condition. Some of the five objectives of restoration are restored or improved (Figure 1). Since complete restoration to the original ecological system is almost impossible, rehabilitation is usually a more general goal of the stream restoration project, and is also significant in terms of river engineering.

\subsection{Remediation}

In some cases, even rehabilitation is not possible because of the irretrievable changes to the original stream. The original state is no longer a proper aim of the stream design because inputs and outputs from the present damaged catchment are not suitable for the original condition. In this situation, the suitable treatment is remediation [29]. The aim of remediation is to improve the ecological condition of the stream, but the endpoint of that improvement will not necessarily resemble the original state of the stream (Figure 1). In fact, it is difficult to predict what a stream will look like after the remediation, and it would mean a new artificial stream that is completely different from the existing one.

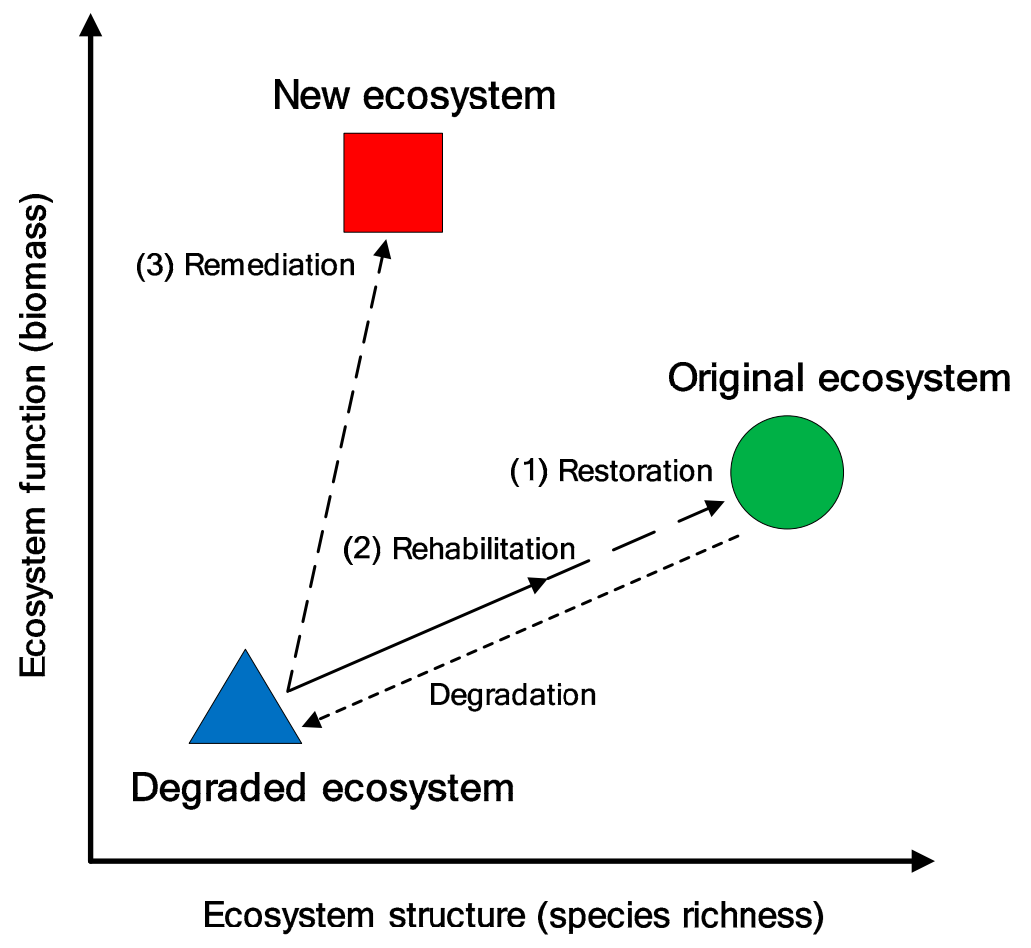

Figure 1. Conceptual diagram of restoration, rehabilitation, and remediation [18]: (1) restoration involves returning the stream to the original ecosystem condition, (2) rehabilitation involves fixing only some aspects of the stream, but generally makes the degraded stream closer to the original condition, (3) remediation is the state that is no longer irreversible to the original conditions and it aims for an entirely new condition. Thus, the broad restoration extends rehabilitation and remediation as well as restoration. However, in this study, stream restoration was limited to stream rehabilitation.

\section{Representative Guidelines for the Stream Restoration}

\subsection{Stream Corridor Restoration Principle, Processes, and Practice}

The technique of the United States Department of Agriculture (USDA) suggested a systematic process to design river restoration [17]: (1) developing a stream restoration plan, (2) analysis of corridor condition, (3) restoration design, (4) restoration implementation, monitoring, and management. The sequence of restoration provided in this guideline is as follows. 
(Step 1) Defining the components of the stream corridor and introducing the concepts of scale and structure. With these concepts, structural elements within the stream corridor are examined in the lateral and longitudinal dimensions.

(Step 2) Presenting information on the hydrologic and geomorphic processes that help build structures in the stream corridor. In addition, this step includes addressing the chemical and biological characteristics that make a stream corridor unique in the landscape.

(Step 3) Summarizing the range of disturbances that can stress the stream corridor ecosystem, impact dynamic equilibrium, and impair the corridor's ability to perform critical functions. Both natural and human-induced disturbances are discussed with a special emphasis on land use activities.

(Step 4) When introducing the first two steps of plan development, the first portion of this step focuses on the basics of getting organized and presents key steps that should be undertaken to initiate the restoration process. The remainder of this step centers on problem/opportunity identification and introduces the basics of the stream corridor condition analysis and problem assessment.

(Step 5) Presenting information concerning how restoration goals and objectives are identified and how alternatives are designed and selected.

(Step 6) Concluding with a discussion of implementation, monitoring, and evaluation of restoration.

(Step 7) Discussing the measurement and analysis of the corridor condition. The analysis is classified by scale and process, (1) physical processes, structures, and functions, (2) geomorphic and hydrological analysis, (3) water chemistry analysis, and (4) biological analysis.

(Step 8) Containing design guidance and techniques to restore stream corridor structure and function.

(Step 9) Dealing with construction topics that can occur after the stream corridor restoration design is complete and required permits are obtained. Careful construction and field inspection are necessary to ensure that the corridor is not degraded by construction activities. At the end of a successful restoration, the stream must be maintained and monitored to ensure the goals are met.

\subsection{A Rehabilitation Manual for Australian Streams}

The rehabilitation manual for Australian streams [18] described seven major steps (which breaks into 12 minor steps). It suggested the planning, vision, setting priorities, and problem definition in point of view on the regional or whole-of-catchment scale. As the planning moves to identify solutions, detailed designs, and evaluation, the focus tends to move down in scale to a group of reaches, a single reach, or a single group of stakeholders.

A 12-steps stream rehabilitation procedure was proposed:

(Step 1) Establishment of project goals for rehabilitating the stream

(Step 2) Determination of the stakeholders to share project goals for the stream

(Step 3) Understanding stream change since the people settlement

(Step 4) Understanding main natural assets and problems of the stream

(Step 5) Setting priorities: which reaches and problems should the planner work on first

(Step 6) Establishment of strategies to protect assets and improve the stream

(Step 7) Creation of specific and measurable objectives

(Step 8) Establishment of feasible objectives

(Step 9) Development of the detailed design of the project

(Step 10) Establishment of how to evaluate the project

(Step 11) Establishment of how to plan and implement the project

(Step 12) Maintenance of the project worked 


\subsection{Integrated Manual of Stream Restoration}

The integrated manual of stream restoration [25] has been one of the Korean representative guidelines for the stream restoration. It includes the contents of setting restoration objectives, how to determine restoration reaches, and determining the restoration type in terms of ecological, water quality, water quantity, and riverscape aspects. Figure 2 shows that the different design procedures were proposed, according to the waterfront stream (urban stream), the waterfront and conservation stream (agricultural stream), and the conservation stream (mountain stream), which are selected by the types of stream reach. The design of stream restoration follows the following procedure: (1) selection of a stream reach to restore, (2) characteristic analysis of a stream in watershed, (3) reference analysis of a natural stream or a similar stream, (4) the establishment of restoration goals, (5) the establishment of the master plan, (6) the design of stream restoration, (7) the implementation of the restoration project, (8) monitoring and assessment, (9) a complementary plan and design, project implementation, monitoring, and assessment for designated conservation districts and abandoned channels. The restoration of the channel or abandoned channel was determined by the evaluation of past and present change of the channel (or the assessment of reference streams).

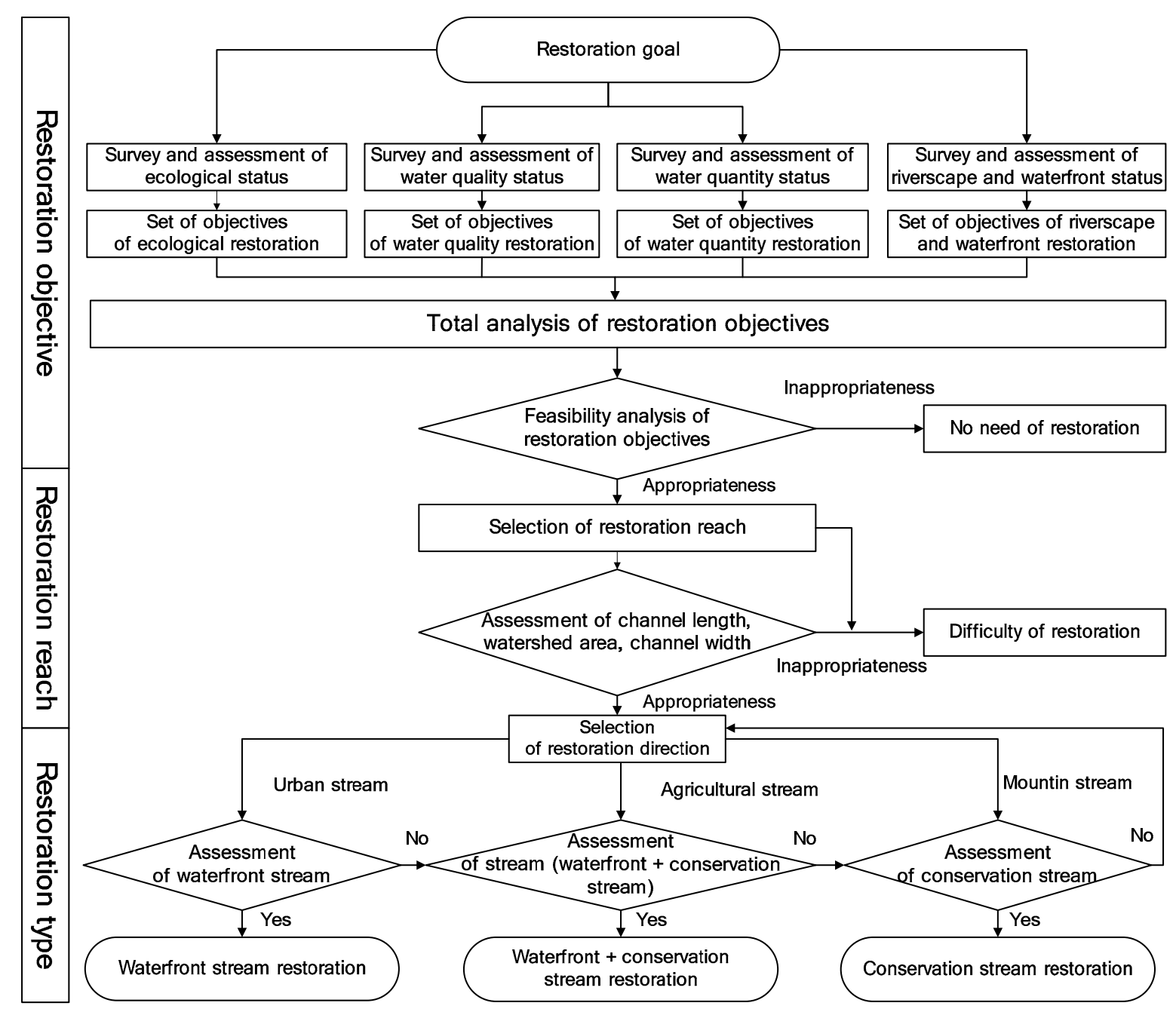

Figure 2. Determination procedure of a restoration direction, according to the types of stream reaches [25]. 


\section{Development of Sustainable Integrated Design Framework for Stream Restoration}

In this study, a complete restoration to the original nature state is very difficult, so the goal is to rehabilitate a relatively close level to the natural state. However, it does not mean a completely different level of river remediation. Thus, we suggested that a broad range of actions and measures be included to enable stream corridors to rehabilitate and recover dynamic equilibrium and function at a self-sustaining close level to the natural state. We developed a formal, new procedure of stream restoration such as close-to-nature stream restoration method to accomplish the objectives of stream restoration, the process of $\mathrm{H} \& H$ analysis under various flow conditions, and $G \& S$ and $E \& E$ analysis. A new design procedure of stream restoration was developed to be suitable for the actual design based on three design phases-three design plans of stream restoration.

\subsection{Stream Restoration Design Procedure Based on the Integrated Watershed Management (IWM) Plan}

IWM was defined as the management of a watershed system with a sustainable technological option [2]. IWM must be considered prior to stream restoration since IWM is an effective method for integrating and dealing with multiple subjects such as water quantity and quality, time strategies, surface and subsurface resources, and participation. Thus, IWM must take measures to mitigate problems caused by stream flow depletion during the period of drought, and must be focused on preventing or reducing flood damage during the flood.

A general, systematic, eleven-step stream restoration procedure from Step 1 to 11 , as shown in Figure 3, was introduced to organize and develop an integrated approach to the closed-to-nature stream restoration procedure. The eleven-step procedure was broadly classified with the pre-restoration design phase, the restoration design phase, and the detailed design phase (Figure 3).

The pre-restoration design phase was comprised of three steps: (step 1) data survey and establishment of goals of stream restoration project, (step 2) flow analysis based on IWM project for target stream, and (step 3) setting $\mathrm{H} \& \mathrm{H}$, geomorphic and sediment transport, and E\&E conditions. Steps 4 to 7 are performed during the restoration design phase: (step 4) design for H\&H plan, (step 5) design for G\&S plan, (step 6) design for E\&E plan, (step 7) selection of the best effective restoration plan by assessment of $\mathrm{H} \& \mathrm{H}, \mathrm{G} \& \mathrm{~S}$, and E\&E plans. Using the most effective design plan, detailed restoration design phase performs steps 8 to 11: (step 8) adding instream structures to improve ecological habitat for target fishes, (step 9) stability assessment using analysis of long-term bed change for the selected restoration design plan, (step 10) estimation of earthwork cost for the best effective restoration design plan, and (step 11) establishment of a master plan. 


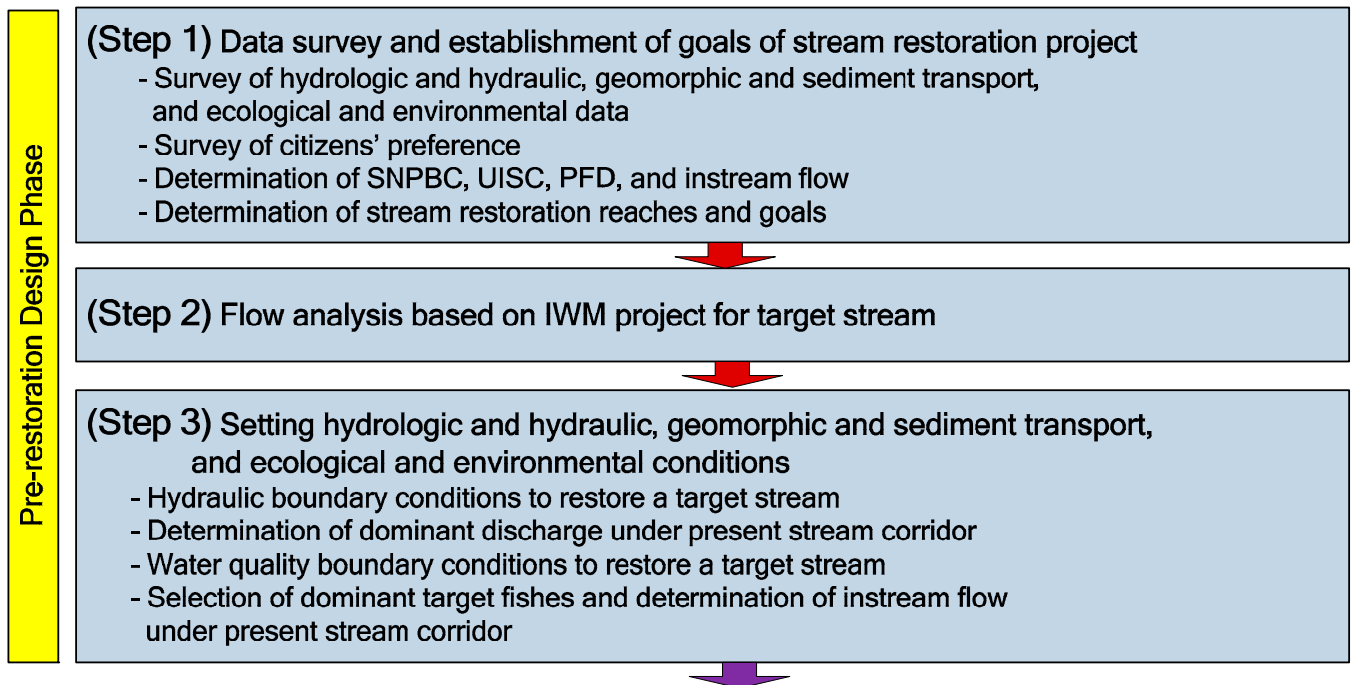

(Step 4) Design for hydrologic and hydraulic plan

- Determination of low-flow and aquatic life criteria (CCC, CMC)

using hydrologically-based design flow method

- Renewal of instream flow based on IWM project

- Design of channel planform and meandering geometry

- Design of channel slope and longitudinal profile

- Design of channel cross section shape

- Design of riffle and pool structures

- Assessment of hydraulic dynamic analysis and stability assessment using tractive force

(Step 5) Design for geomorphic and sediment transport plan

- Channel classification

- Selection of channel evolution scenario

- Stability assessment using long-term bed change

(Step 6) Design for ecological and environmental plan

- Determination of low-flow and aquatic life criteria (CCC, CMC)

using biological-based design flow method

- Determination of fish flow and renewal of instream flow for restored stream

- Design of habitat including vegetation and wetland

- Simulation of water quality model

(Step 7) Selection of the best effective restoration plan

by assessment of hydrologic and hydraulic, geomorphic and sediment transport, and ecological and environmental plans

(Step 8) Adding of instream structures to improve ecological habitat for target fishes

(Step 9) Stability assessment using analysis of long-term bed change for the selected restoration design plan

(Step 10) Estimation of earthwork cost for the best effective restoration design plan

(Step 11) Establishment of master plan

- Drawing works for planform, cross section, longitudinal profiles of stream for hydrologic and hydraulic, geomorphic and sediment transport, and ecological and environmental plans

Figure 3. Stream restoration procedure based on an integrated watershed management (IWM) project. 


\subsection{Development of Stream Restoration Design Procedure Considering HEH Plan, GES Plan, and EEE Plan}

As shown in Figure 3, the three plans consist of three design phases such as the pre-restoration design phase, the restoration design phase, and the detailed restoration design phase with interconnection and interrelationships. In addition, the proposed stream restoration design procedure was divided into three distinct categories such as H\&H plan, G\&S plan, and E\&E plan because the elements of hydrology, hydraulics, geomorphology, environmental, and ecological engineering must be considered important. Thus, the stream restoration procedure shown in Figure 3 should be classified, detailed, and presented as the three important plans. The new flowchart developed in this study has been developed to create a design plan that is linked with the three design phases and the three design plans.

\subsubsection{Hydrologic and Hydraulic (H\&H) Plan}

As shown in Figure 4, the H\&H plan also consisted of three phases such as the above, respectively. The steps to the right of Figure 4 correspond to the steps given in Figure 3.

In pre-restoration design phase of $\mathrm{H} \& \mathrm{H}$ plan, in order to determine the stream restoration reach and establish the goals for the stream restoration project, it was important that the assessment of Stream Naturalness considering Physical, Biological, and Chemical factor (SNPBC), the Use Index of Stream space for Citizen (UISC) to estimate the satisfaction of residents for stream facilities, Potential Flood Damage (PFD) to construct a flood control project by using the pressure-state-response model and the multicriteria decision making theory, and instream flow without the IWM under a present watershed and channel conditions were determined by survey of H\&H data based on citizens' preference. The dominant discharges under the present stream corridor were determined by using the flow analysis based on the IWM project. In the step, the computed dominant discharges were bank full discharge, specific recurrence interval discharge, or effective discharge. Dominant discharges can be used to conduct stable channel design and stability analysis using long-term bed change. The hydraulic boundary conditions for a target stream reach were set to use the input data of numerical models. Lastly, under present stream corridor conditions, the instream flow based on the IWM project was updated compared to that without the IWM.

In a restoration design phase of the $\mathrm{H} \& \mathrm{H}$ plan, as active steps to conduct stream restoration design, the low-flow and aquatic life criteria such as the Criterion Continuous Concentration (CCC) and the Criterion Maximum Concentration (CMC) using hydrologically-based design flow method were computed with respect to hydrologic aspect. Instream flows based on IWM project could be renewed by comparing low-flows with instream flow determined in the previous step. As hydraulic channel design steps, the channel platform, longitudinal profile, cross sections, and sinuosity were determined by empirical geometry formulas to design a stable channel. Thus, the hydraulic dynamic properties (i.e., water surface elevation, velocity, and tractive force for design flood discharge, dominant discharge, median flow, and low flow to evaluate flood conveyance and the determination of stable channel and to maintain appropriate depth and velocity) were analyzed to perform the hydraulically stable stream design. In order to protect the channels and levee banks, revetments shall be installed where channels and banks are vulnerable to erosion by the stability analysis using tractive force for the design flood. At the end of the stream restoration design, an evaluation of the hydraulic design should be performed with respect to hydraulic aspects such as the prevention of flooding and maintenance of stable riverbeds. The most effective design could be chosen as the best design of the H\&H plan, G\&S plan, and E\&E plan.

In a detailed restoration design phase of $\mathrm{H} \& \mathrm{H}$ plan, the stream reaches were determined to install instream structures by the assessment of the Weighted Usable Area (WUA) of the fish habitat. When the proper hydraulic and ecological conditions were not met as an ecological habitat for target fish, an appropriate instream structure was selected to perform river restoration. For the best restoration design, we performed a stability analysis using long-term bed change simulation to reconfirm stable channel. Therefore, H\&H plan was established at the end of the detailed restoration design phase. 


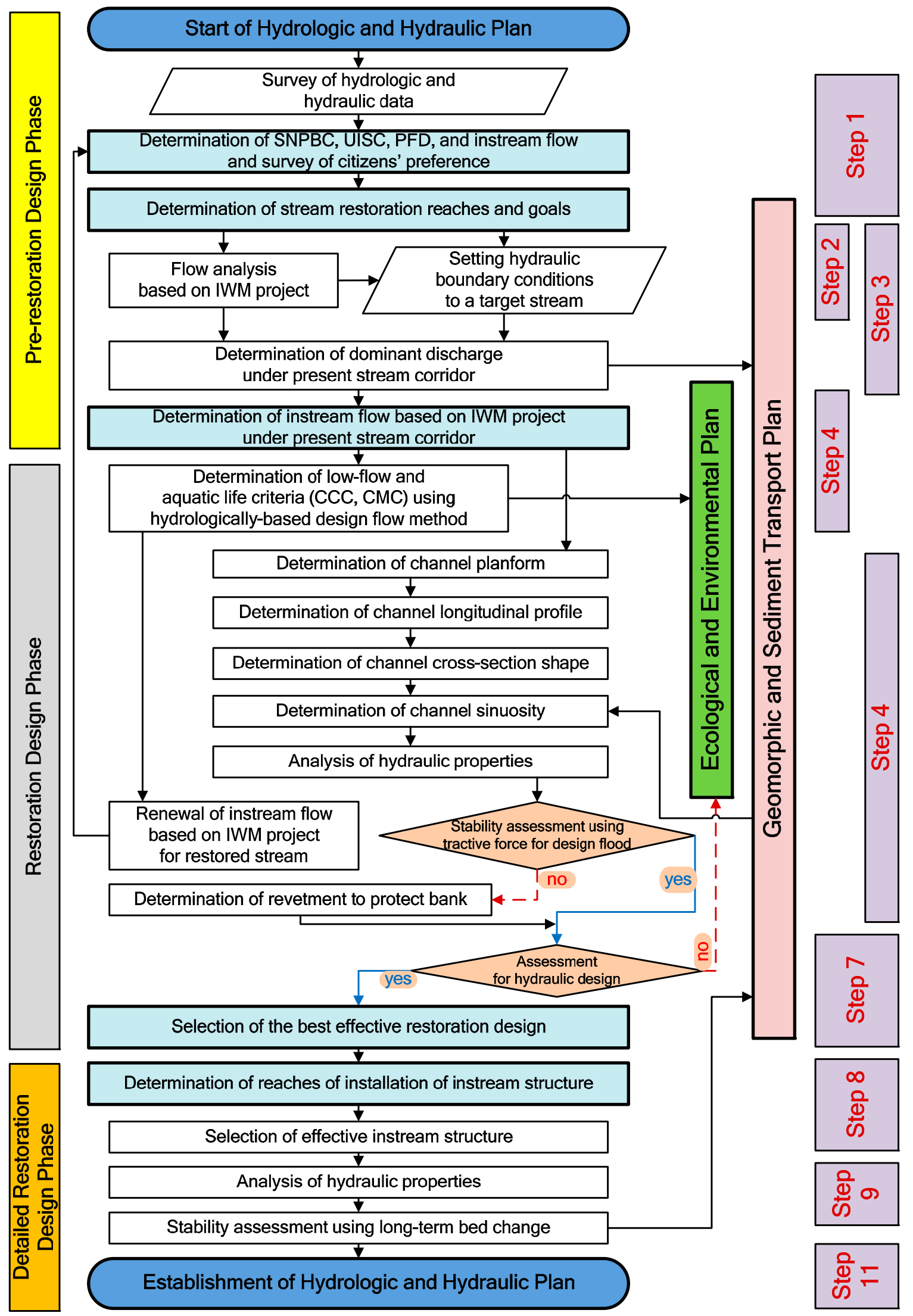

Figure 4. Flow chart for the H\&H plan. 


\subsubsection{Geomorphic and Sediment Transport (G\&S) Plan}

The G\&S plan was shown in Figure 5 from a pre-restoration design phase to a detailed restoration design phase.

In the pre-restoration design phase, the G\&S plan was carried out in the same process as the H\&H plan. Geomorphic and sediment data were surveyed to assess SNPBC, UISC, and PFD and to determine instream flow under current watershed conditions without considering the IWM. Using this process, the stream restoration sites and goals were established for the stream restoration project. In the last phase of the pre-restoration design, the dominant discharges of the stream restoration sites were determined. The dominant discharge became the basis for stream restoration design and should be determined in advance as an important design discharge to determine the appropriate height of the floodplain.

During the restoration design phase of the G\&S plan, stream types could be quantitatively determined for entrenchment, channel form, width/depth ratio, sinuosity, slope, and channel materials using stream classification [30]. According to the types of stream, a channel evolution scenario can be selected to determine the goals and directions of stream restoration based on the stream type. If there is a record of the natural state stream in the past, the restoration goal could be taken by referring to the reference stream. However, in the absence of a suitable reference stream, it is recommended in a reasonable way to determine the shape of the stream by the channel evolution scenario.

Selected channel evolution scenario was used as input for an H\&H plan. A hydraulic stable channel design was performed in the $\mathrm{H} \& \mathrm{H}$ plan using the selected channel evolution scenario. Once the design of the hydraulic stability channel was completed, a stability analysis using the tractive force for design flood discharge and dominant discharge was performed to verify the stable channel design. In the final phase of the restoration design, a geomorphic design was performed in terms of the adequacy of the restoration to the reference stream and the appropriate channel evolution of the design objectives to assess whether the topographical design was performed correctly. However, stability analysis using long-term bed changes was implemented to confirm stable channels, if necessary. In the last step of the restoration design phase, we could select the most effective restoration design for G\&S planning.

During detailed restoration design phase of G\&S plan, optimal restoration design was determined by the long term bed change assessment. To assess the economic feasibility of the stream restoration design, earthworks were estimated considering the final stable stream design and the environmental stream design. Thus, at the end of detailed restoration design phase, the G\&S plan was established. 


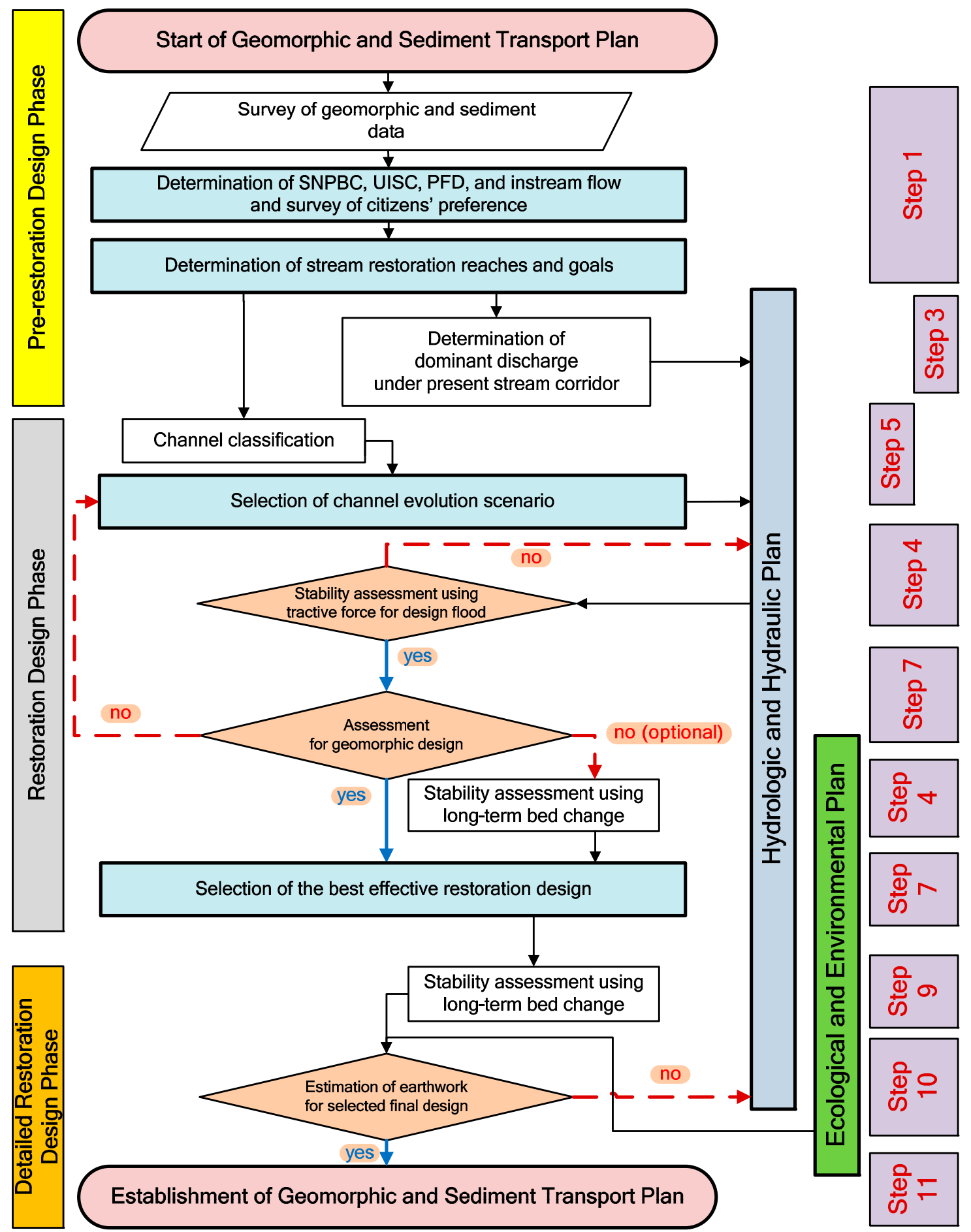

Figure 5. Flow chart for the G\&S plan.

\subsubsection{Ecological and Environmental Plan}

The E\&E plan was shown in Figure 6 from a pre-restoration design phase to a detailed restoration design phase.

In the pre-restoration design phase, the E\&E plan was performed in the same way of the $\mathrm{H} \& \mathrm{H}$ plan and the G\&S plan. The E\&E data were surveyed to assess SNPBC, UISC, and PFD, and to determine instream flow under current watershed conditions without considering the IWM. In the phase, the actual conditions of the drought flow, ecological flow, and current environment condition 
were estimated from the actual target stream before restoration. For the ecological aspect, after the target fish were determined based on the ecological survey data, the flow rate, which satisfy the preferred habitat conditions such as the velocity and the depth of water, should be determined. This flow rate (discharge) was called the ecological flow and is determined in the current river corridor. It was calculated within the range of the drought flow already determined in the hydrologic plan. In order to establish an ecosystem restoration plan for the establishment of the fish habitat as an important step in the pre-restoration phase. Thus, the typical flow rate of an ecological flow can be considered as a fish flow for the restoration of a fish habitat. The maximum flow rate between drought flow and fish flow should be determined as the instream flow of the target stream. For the environmental aspects, the target of water quality were established based on environmental survey data. The water quality target should be determined by closely considering the fish habitat conditions of the ecological restoration. The boundary conditions of water quality were determined based on the collected water quality data. If the boundary conditions were required at the reach without survey data, we could estimate the boundary values at that reach not observed by the dilution equation. However, if the fish flow was greater than the drought flow, prior to the design of stream restoration, IWM should be considered first and the alternatives of water resources security should be established at the last step of the pre-restoration design phase.

As active steps to conduct stream restoration design in restoration design phase of E\&E plan, low-flow and aquatic life criteria (based on frequencies and durations specified in water quality criteria for each pollutant and whole effluents) using hydrological and biological design flow methods were calculated from ecological and environmental perspective. When IWM is considered, the fish flow to the design channels determined by hydrologic and hydraulic planning was recalculated whether fish flow was appropriate for the formation of ecological habitat. However, if IWM is not considered, recalculation of fish flow was omitted during the restoration design phase. Detailed design of vegetation and wetland for the formation of fish habitats was carried out. Water quality simulation was performed using design channels to verify that the target quality was satisfied after stable channel design. Instream flow based on the IWM project could be updated by comparing low-flows with fish flow determined in the previous step. The most effective restoration design could be selected in the last step of restoration design phase for the E\&E plan.

In the detailed restoration design phase of the E\&E plan, the spatial distributions of the ecological habitat were confirmed by calculating WUA in two dimensions without considering the installation of the instream structure. However, if necessary, instream structures using hydraulic dynamics may be installed to maximize WUA under the same flow conditions to improve the effective ecological habitat for target fish. The E\&E plan was established at the end of the detailed restoration design phase.

As shown in Figure 7, a sustainable integrated stream restoration design framework could be completed by combining the three previous plans such as the H\&H plan (Figure 4), the G\&S plan (Figure 5), and the E\&E plan (Figure 6). Therefore, in the last step of the detailed restoration design phase, as shown in Figure 7, a master plan could be proposed for all three plans. 


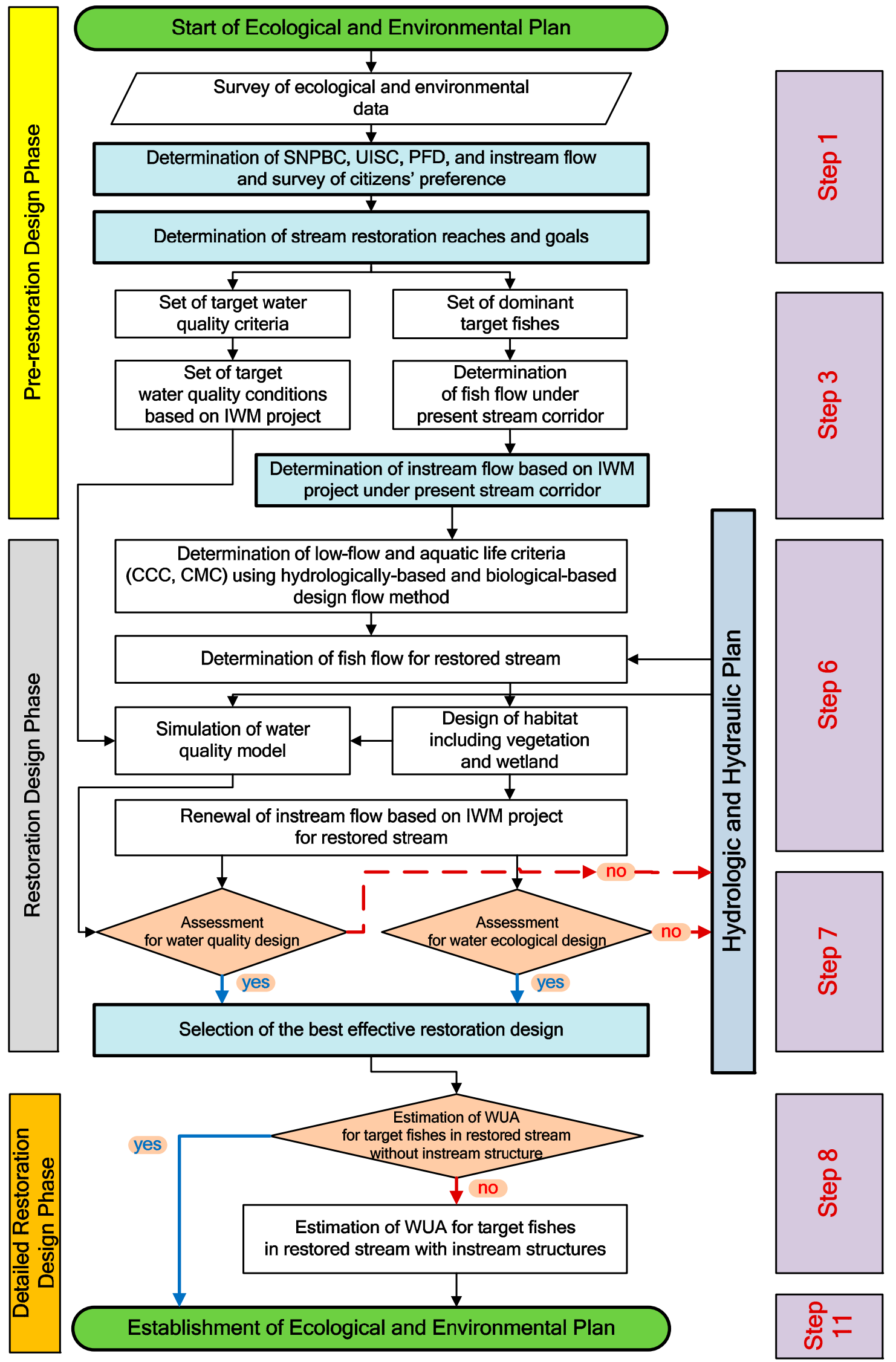

Figure 6. Flow chart for the E\&E plan. 


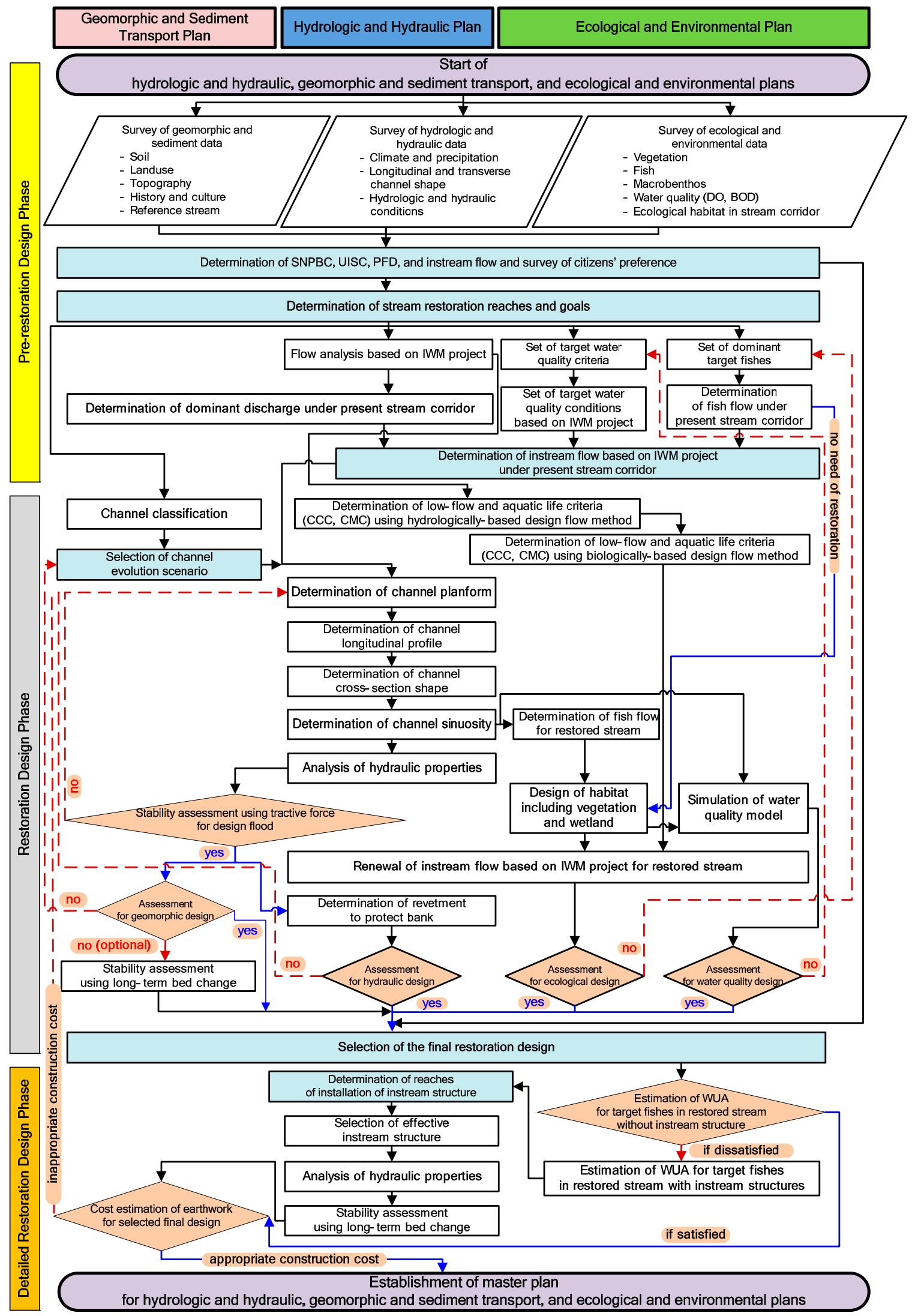

Figure 7. Flow chart of novel design procedure for stream restoration. 


\subsubsection{Numerical Models for the Stream Restoration Project}

Figure 8 shows the flow chart of the numerical model input and output data for stream restoration. It presents the models necessary for $\mathrm{H} \& H, \mathrm{G} \& S$, and E\&E design plans, respectively. As shown in Figure 8, we proposed the use of five models such as the Storm Water Management Model (SWMM) [31], the Hydrologic Engineering Center River Analysis System (HEC-RAS) [32], Design FLOWs (DFLOW) [33], Physical HABitat SIMulation (PHABSIM) [34], and River2D [35].

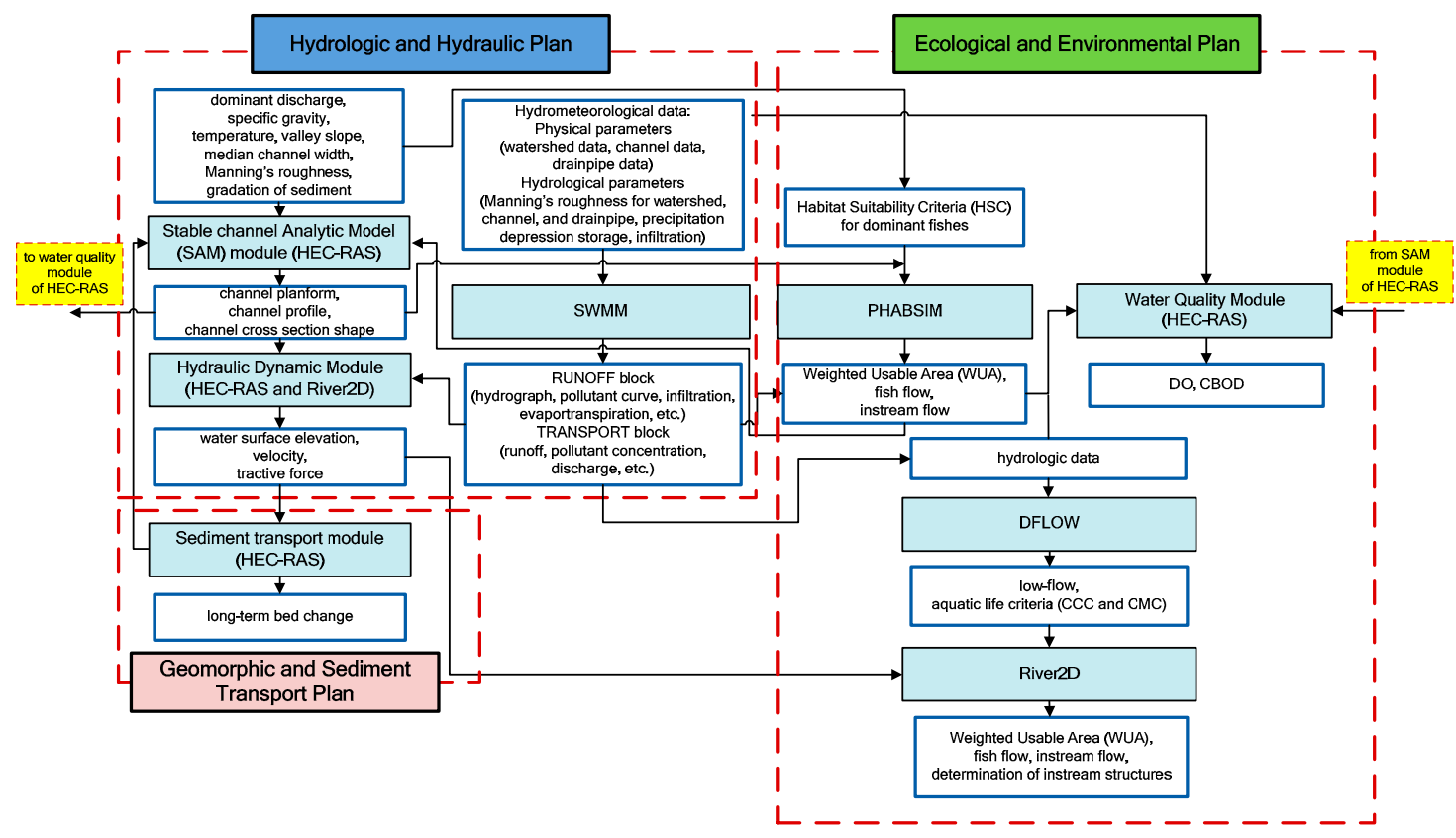

Figure 8. Flow chart of numerical model input and output data for the stream restoration project.

A hydrologic and hydraulic plan, as shown in Figure 8, used a total of three models. The SWMM was utilized with hydrological data including precipitation, infiltration, and depression storage as well as physical data on watershed data, channel data, and drainpipe data as input of SWMM. The output of the SWMM was calculated as hydrograph, pollutant curve, and evaporation in RUNOFF block, and as runoff, pollutant concentration, and discharge in the TRANSPORT block. The results of runoffs and discharges of the SWMM were used as input data for the DFLOW and the HEC-RAS. For each design condition of the channel for stream restoration design, drought flow, low flow, flood flow, and dominant discharge were available as flow boundary conditions of HEC-RAS. In the case of Stable channel Analytic Model (SAM) module in HEC-RAS, it was possible to calculate the stable channel using the physical observation data (e.g., specific gravity, valley slope, median channel width, roughness, gradation of sediment) and using dominant discharge and flood flow rate calculated from the SWMM. SAM calculated the stable channel by using the Copland method, the regime method, and the tractive method. In this study, we recommended the Copland method, which could calculate the median channel width using channel forming discharge (bankfull discharge): stable slope could be determined using the median channel width and stability curve by channel forming discharge [36]. It is an effective method to determine stable channel by using only sediment concentration of upstream, dominant discharge, and gradation of sediment $\left(D_{84}, D_{50}\right.$ and $\left.D_{16}\right)$ as input data without the simulation of long-term bed change. Thus, it is possible to determine planform, profile, and the cross section of the stable channel. The hydraulic dynamic models (steady uniform flow or unsteady flow) of HEC-RAS was used to determine the water surface elevations, velocities, and tractive forces, according to the flow rate changes (e.g., flood discharge, dominant discharge, drought flow) on the determined stable channel. The heights of floodplain and levee required for restoration design along the stream corridor could be determined by determined water surface elevations and discharges based on the topographic 
data of a stable channel. To protect the main channel and side slope of the channel bank, revetments were installed in locations vulnerable to erosion that exceeded the allowance for tractive force for the design flood discharge or dominant discharge. In addition, the boundary conditions of water surface elevations by flow rates were calculated using the hydraulic dynamic models of HEC-RAS, since the two-dimensional hydraulic dynamic model and the two-dimensional ecological habitat model required the boundary conditions of water surface elevations at the restoration sites by discharges.

For the G\&S plan, the simulation of long-term bed changes using the sediment transport module of HEC-RAS could be performed to assess the stable channel bed of dynamic equilibrium. The assessment using long-term bed variations was reaffirmed after completion of the stability assessment using the traction forces for design flooding during the hydraulic design phase. If the previously mentioned Copeland method of SAM was used, the simulation of long-term bed changes can be carried out for additional needs since the Copeland method already included the calculation of forming a stable channel.

For the E\&E plan, a total of four models are available as shown in Figure 8. In order to consider stream restoration of the ecological aspect, PHABSIM, a one-dimensional ecological habitat model, used the target fishes using the Habitat Suitability Criteria (HSC) [34] to calculate the optimal flow rate for the target fish based on the channel geometric and hydrologic data. This calculated the ecological flow that was called fish flow, and the calculated flow such as the drought flow from the $\mathrm{H} \& \mathrm{H}$ plan, which was compared with fish flow to obtain the maximum flow rate to determine the instream flow at the restoration sites [6]. To consider the stream restoration of environmental aspects, the environmental criteria such as the CCC and CMC that satisfy the aquatic life criteria could be calculated using the DFLOW to predict the water quality conditions after stream restoration without direct calculation of the water quality $[6,33,37]$. In addition, using the water quality module in the HEC-RAS, it is also possible to determine directly whether the environmental conditions such as Dissolved Oxygen (DO), Biochemical Oxygen Demand (BOD), and Carbonaceous Biochemical Oxygen Demand (CBOD) at the stream restoration site meet the target conditions of water quality by using meteorological and hydrologic conditions, and environmental boundary conditions as input data of the water quality module. The physical spatial distribution of the ecological habitat could be expected using the two-dimensional ecological model, River2D, to effectively create the two-dimensional spatial distribution of the habitats for the target species. If the proper spatial environment for the target fish was insufficient due to insufficient flow rate and ecological conditions, River2D was able to assess the adequacy of the two-dimensional habitats after installing various instream structures such as vanes, spurs, weirs, riffles, stepping-stones, and more. [38].

Therefore, the proposed numerical models in Figure 8 should be considered the minimum in performing the stream restoration plan and design. In order to perform three aspects (i.e., the $H \& H$, G\&S, E\&E design plans) of stream restoration effectively and quickly, stream restoration could be performed using the sequence shown in Figure 8.

\section{Application}

As shown in Table 1, the proposed stream restoration procedure was compared to the typical stream restoration guidelines and past representative stream restoration practices in Korea. Compared with the elements proposed in this study, the existing guidance and the case study considered elements of stream restoration design. However, a score of 1 was given if they did not provide an example applicable to the stream or were not considered sufficiently. In addition, a score of 2 was given if the restored elements were properly reflected. A score of zero was given when no restoration element was considered. By weighing the entire design elements with the same weight, we found weaknesses in existing restoration guides and identified problems in actual cases of stream restoration.

As shown in Table 1, the Mokgamcheon stream restoration project of Saman \& Hankuk Engineering Consultants [8] considered only hydraulic design using HEC-RAS. It did not consider 
the G\&S aspect and the E\&E aspect except for the survey and observation for geomorphic, ecological, and environmental data. The Mokgamcheon stream restoration by Saman \& Hankuk Engineering Consultants was similar to the previous channel adjustment project or channel modification projects with ecological landscape design that had no basis in hydrologic and hydraulic aspect, the G\&S aspect, and the E\&E aspect. The ECORIVER21 technical report [24] and integrated manual of stream restoration [25] proposed a Korean stream restoration guideline. However, they were poor in applying an example of stream restoration to be used in an actual stream restoration project. As shown in Table 1, the H\&H aspect, the G\&S aspect, and the E\&E aspect were considered in the technical report and integrated manual. However, in hydrologic \& hydraulic aspect, IWM project, low-flow, aquatic life criteria such as CCC and CMC, and the River2D analysis were not considered. In a G\&S aspect, the channel evolution scenario and estimation of earthwork were not considered. In the E\&E aspect, aquatic life criteria such as CCC and CMC and installation of instream structures were not proposed. In the case of restoration cases as shown in Table 1, the total score is 5 points and the restoration rate is $12.5 \%$, which is not considered to be the case for stream restoration. In the case of technical report and manual, the total score is 21 points, $52.5 \%$, which is insufficient to be the guideline for which all three elements are considered.

Table 1. Evaluation on an actual stream restoration project and a technical report and manual.

\begin{tabular}{|c|c|c|c|}
\hline Plan & $\begin{array}{l}\text { Element of Stream Restoration } \\
\text { (Maximum Score) }\end{array}$ & $\begin{array}{c}\text { Mokgamcheon } \\
\text { Stream Restoration } \\
\text { Project }\end{array}$ & $\begin{array}{l}\text { Technical Report } \\
\text { and Manual of } \\
\text { ECORIVER21 }\end{array}$ \\
\hline \multirow{11}{*}{$\begin{array}{l}\text { Hydrologic and } \\
\text { hydraulic }(\mathrm{H} \& \mathrm{H}) \\
\text { plan }\end{array}$} & IWM project (2) & 0 & 0 \\
\hline & $\begin{array}{l}\text { Assessment of SNPBC, UISC, and PFD, } \\
\text { and survey of citizens' preference (2) }\end{array}$ & 0 & 1 \\
\hline & Flow duration curve (2) & 0 & 2 \\
\hline & Design flood discharge (2) & 2 & 2 \\
\hline & Dominant discharge (2) & 0 & 2 \\
\hline & $\begin{array}{l}\text { Low-flow and aquatic life criteria (CCC and CMC) } \\
\text { using hydrologically-based design flow method (2) }\end{array}$ & 0 & 0 \\
\hline & Stable channel design using empirical formula (2) & 0 & 2 \\
\hline & Stable channel design using SAM (2) & 0 & 2 \\
\hline & HEC-RAS (2) & 2 & 2 \\
\hline & River2D (2) & 0 & 0 \\
\hline & Effective instream structures (2) & 0 & 1 \\
\hline \multirow{4}{*}{$\begin{array}{l}\text { Geomorphic and } \\
\text { Sediment } \\
\text { transport (G\&S) } \\
\text { plan }\end{array}$} & Channel classification (2) & 0 & 2 \\
\hline & Channel evolution scenario (2) & 0 & 0 \\
\hline & Long-term bed change (2) & 0 & 2 \\
\hline & Estimation of earthwork (2) & 0 & 0 \\
\hline \multirow{4}{*}{$\begin{array}{l}\text { Ecological and } \\
\text { Environmental } \\
\text { (E\&E) plan }\end{array}$} & $\begin{array}{l}\text { Low-flow and aquatic life criteria (CCC and CMC) } \\
\text { using biologically-based design flow method ( } 2 \text { ) }\end{array}$ & 0 & 0 \\
\hline & Water quality numerical simulation (2) & 0 & 1 \\
\hline & Fish flow (2) & 0 & 1 \\
\hline & Installation of instream structures (2) & 1 & 1 \\
\hline & Total score & 5 & 21 \\
\hline \multicolumn{2}{|c|}{ Average rate of restoration elements (\%) } & 12.5 & 52.5 \\
\hline
\end{tabular}

\section{Results and Discussion}

Based on the results in Table 1, the results of this study were analyzed for excellence and utilization. Sustainable integrated stream restoration design procedures such as three phases and three plans presented in this study was able to effectively determine the problems of existing river restoration 
projects and to determine whether the restoration procedures of $H \& H, G \& S$, and E\&E design plans were properly considered. Therefore, if part of a particular design step is missing or not considered, then the design restoration after that stage has not been performed properly and is not a fully planned stream restoration. The analysis results of the application cases in this study led to the following results. The two examples compared in Table 1 were applicable to urban streams suffering from water shortages due to climate change. In this case, it was essential to establish a sufficient water supply plan considering the IWM prior to the river restoration plan and to establish a restoration plan on the ecological and environmental aspects. However, the two examples analyzed in this study did not take into account the IWM at all even though the various water shortages caused by the urban stream were serious. Therefore, the consideration of the IWM in the pre-restoration design phase (Figure 3) proposed in this study could be assessed in a more effective way than the stream restoration method applied in the existing actual cases where water security aspects were not taken into account at all. This means that, prior to performing restoration of the stream, an effective pre-restoration design phase can be carried out using the water resources secured by the IWM. Therefore, the proposed river restoration procedure has the advantage of eliminating the possibility of problems occurring during the pre-restoration design phase due to the lack of water that may occur during the restoration design phase.

The detailed analysis results of H\&H plan applied to the restoration project of the Mokgamcheon stream, as shown in Table 1, was as follows. The sufficient flow rate of stream restoration should be ensured through the IWM measures, but it was not considered in this river restoration project. In the pre-restoration design phase, the goals of stream restoration must be set through the assessment of SNPBC, UISC, PFD, and survey of citizens' preference. However, in this case, the basis for river restoration targets was very weak. The bases for calculating the flow duration curve and the dominant discharge on hydrologic aspects for determining hydraulic boundary conditions were not found in the restoration project and only the flood discharge was calculated. The project did not take into account the desirability of hydrological environments through the calculation of low-flow. Stable channel design that satisfies the stable channel conditions for stream restoration was also not considered. Therefore, this river restoration project cannot be seen as an integrated stream restoration project because only flood control aspects are considered in the H\&H plan. In the Mogamcheon stream restoration project in Table 1, there was no consideration at all for the G\&S plan, such as channel classification and evolution scenario, which are the basis for establishing river restoration targets. In addition, there was no estimation of dynamic equilibrium bed formation by calculating the long-term-term bed change after river restoration. Although determining the volume of earthwork is very important as an economic indicator for river restoration, the calculation of earthworks volume was not considered. In the case of the application of the E\&E plan in the Mokgamcheon restoration project, the low-flow had to be calculated to review the satisfaction of the biological water environment conditions for the aquatic life. However, this had not been considered either. The ecological flow rates, such as fish flows, were not calculated. For ecological stream restoration, fish flows must be considered in order to create a proper ecological habitats for target species. If the instream structures were installed without any hydraulic dynamic and ecological habitat simulations, such as the Mokgamchen restoration project, they could adversely affect the restored river from both the hydraulics and ecological aspects. Water quality numerical simulation for verifying satisfaction with the target water quality of the restored Mokgamchen was also not performed.

As shown in Table 1, in case of the technical report and manual of ECORIVER21, application of IWM and actual restoration methods required for restoration objectives and calculation of low-flow were not considered. The river restoration guidelines presented in the technical report and manual were limited and were far from integrated and detailed methods of restoration. Thus, a sustainable and integrated stream restoration plan will be established using a flow chart of numerical models presented in this study (Figures 7 and 8). 
Therefore, the assessment of the restoration elements obtained from this study provided a basis for assessing whether the elements of stream restoration were considered sufficiently, and when the restoration plan was established, the sustainable integrated direction of stream restoration could be supplemented with the addition of insufficient elements to establish the restoration plan. This study could be useful in providing guidance on the direction of stream restoration to government officials and engineers by providing strength and weakness for planning and implementing stream restoration projects, which proposed restoration elements that were compared with the currently conducted stream restoration projects.

\section{Conclusions}

Novel and detailed "three design phases-three design plans of restoration procedure" was developed as a practical stream restoration method adapted to Korean streams. A general, systematic, 11-step stream restoration procedure was developed and suggested as an integrated restoration approach. First, the three restoration design phases include the pre-restoration design phase that considers the IWM plan, a restoration design phase, and a detailed restoration design phase. Second, the three restoration plans include the H\&H, G\&S, and E\&E plans.

The pre-restoration design phase was comprised of three steps such as data survey and an establishment of goals of the stream restoration project, flow analysis based on the IWM project for the target stream, and setting the H\&H, G\&S, and E\&E conditions. During the restoration design phase, the selection of the best effective restoration plan by assessing the H\&H, G\&S, and E\&E plans was implemented. The following detailed design phase included adding the instream structure to improve an ecological habitat for target fishes, a stability assessment using analysis of a long-term bed change for the selected restoration design plan, estimation of earthwork cost for the best effective restoration design plan, and establishment of the master plan. To implement restoration design for the H\&H, G\&S, and E\&E design plans, at least five numerical models (e.g., PCSWMM, DFLOW, HEC-RAS, PHABSIM, and River2D) were proposed to establish an effective the river restoration plan.

This novel three-three procedure was compared with that of the Mokgamcheon stream restoration project and technical report and integrated manual of stream restoration as representative examples. The Mokgamcheon stream restoration project did not consider the G\&S and E\&E aspects except the survey and observation for geomorphic, ecological, and environmental data but it considered only hydraulic design using HEC-RAS. The restoration case was similar to the previous channel adjustment or modification projects with an ecological landscape design. A technical report and integrated manual of stream restoration proposed a Korean stream restoration guideline. However, they were poor in applying an example of stream restoration to be used in an actual stream restoration project. Although $\mathrm{H} \& \mathrm{H}, \mathrm{G \& S}$, and E\&E aspects were considered in a technical report and an integrated manual. However, in hydrologic and hydraulic aspect, IWM project, low-flow, aquatic life criteria such as CCC and CMC, River2D analysis were not considered. In the G\&S aspect, the channel evolution scenario and estimation of earthwork were not considered. In the E\&E aspect, aquatic life criteria such as CCC and CMC and installation of instream structures were not proposed. Therefore, in the case of the Mokgamcheon stream restoration project, further consideration of the G\&S and E\&E elements was required since only the calculation of flood discharges and flood water levels for flood control and the installation of instream structures in the aspect of river landscape were considered during the restoration design phase. In the case of the technical report and manual of ECORIVER21, guidelines were not provided for the use of numerical models, which are essential to stream restoration and the procedure for stream restoration even though each design element of restoration design phases needed for river restoration are presented.

It will be useful and meaningful for the stream restoration project that this study proposed in a new stream restoration design procedure based on $\mathrm{H} \& \mathrm{H}, \mathrm{G} \& \mathrm{~S}$, and $\mathrm{E} \& \mathrm{E}$ aspects. In addition, the restoration components proposed in this study would be provided to assess whether the stream restoration plan has been properly established. This stream restoration framework was proposed 
and it was very useful in providing government officials and hydraulic engineers with a guideline for planning and implementing stream restoration projects. Therefore, river restoration projects can be planned and proposed effectively and comprehensively in accordance with the sustainable and integrated stream restoration design method presented in this study. In addition, based on the value of this research, achievements will be highly evaluated because river developers or designers can use it as an index to objectively evaluate plans of the stream restoration.

Author Contributions: Conceptualization, K.P. and K.S.L. Methodology, K.P., and K.S.L. Software, K.P. Validation, K.P. Formal Analysis, K.P. Investigation, K.P. and K.S.L. Resources, K.P. Data Curation, K.P. Writing-Original Draft Preparation, K.P. Writing-Review \& Editing, K.P. and K.S.L. Visualization, K.P. Supervision, K.S.L. Project Administration, K.S.L. Funding Acquisition, K.S.L.

Funding: This work was supported by the Institute of Engineering Research at Seoul National University and the Department of Civil \& Environmental Engineering at Seoul National University.

Acknowledgments: Park, K. and emeritus prof. Lee, K.S., corresponding authors, acknowledged the financial support of the Institute of Engineering Research at Seoul National University and the Department of Civil \& Environmental Engineering at Seoul National University.

Conflicts of Interest: The authors declare no conflict of interest.

\section{References}

1. Lee, K.S.; Chung, E.-S.; Kim, Y.O. Integrated watershed management for mitigating stream flow depletion in an urbanized watershed in Korea. Phys. Chem. Earth 2008, 33, 382-394. [CrossRef]

2. Lee, K.S.; Chung, E.S. Development of integrated watershed management schemes for an intensively urbanized region in Korea. J. Hydro-Environ. Res. 2007, 1, 95-109. [CrossRef]

3. Woo, H. Trends in ecological river engineering in Korea. J. Hydro-Environ. Res. 2010, 4, 269-278. [CrossRef]

4. Jiang, H.; He, C.; Luo, W.; Yang, H.; Sheng, L.; Bian, H.; Aou, C. Hydrological restoration and water resources management of Siberian Crane (Grus leucogeranus) stopover wetlands. Water 2018, 10, 1714. [CrossRef]

5. Lee, J.H.; Kil, J.T.; Jeong, S. Evaluation of physical fish habitat quality enhancement designs in urban streams using a 2D hydrodynamic model. Ecol. Eng. 2010, 36, 1251-1259. [CrossRef]

6. Park, K.; Lee, K.S.; Kim, Y.-O. Use of instream structure technique for aquatic habitat formation in ecological stream restoration. Sustainability 2018, 10, 4032. [CrossRef]

7. William, P.B. River engineering versus river restoration. In Proceedings of the ASCE Wetlands Engineering \& River Restoration Conference 2001, Reno, NV, USA, 27-31 August 2001.

8. Saman and Hankuk Engineering Consultants. Master Plan and Detailed Design of the Mokgamcheon Restoration; Saman and Hankuk Engineering Consultants: Gwang Myeong City, Korea, 2008.

9. Copeland, R.R.; McComas, D.N.; Thorne, C.R.; Soar, P.J.; Jonas, M.M.; Fripp, J.B. Hydraulic Design of Stream Restoration Projects; ERDC/CHL TR-01-28; Coastal and Hydraulics Laboratory, Engineer Research and Development Center, United States Army Corps of Engineers: Washington, DC, USA, 2001.

10. Jowett, I.G. Instream flow methods: A comparison of approaches. Regul. Rivers Res. Manag. 1997, 13, 115-127. [CrossRef]

11. Pathak, N.; Girija, T.R.; Mahanta, C. Modeling application towards eco-restoration strategies for the polluted tributaries of the Brahmaputra River system. In Proceedings of the World Environmental and Water Resources Congress 2007: Restoring Our Natural Habitat, Tampa, FL, USA, 15-19 May 2007.

12. Kondolf, G.M. Lessons learned from river restoration projects in California. Aquat. Conserv. Mar. Freshw. Ecosyst. 1998, 8, 39-52. [CrossRef]

13. Palmer, M.A.; Benhardt, E.S.; Allan, J.D.; Lake, P.S.; Alexander, G.; Brooks, S.; Carr, J.; Clayton, S.; Dahm, C.N.; Follstad Shah, J.; et al. Standards for ecologically successful river restoration. J. Appl. Ecol. 2005, 42, $208-217$. [CrossRef]

14. Dunster, J.; Dunster, K. Dictionary of Natural Resource Management; University of British: Vancouver, BC, Canada, 1996.

15. United States Army Corps of Engineers. Hydraulic Design of Flood Control Channels; EM1110-2-1601; SACE Headquarters: Washington, DC, USA, 1991. 
16. Stalnaker, C.B.; Lamb, B.L.; Henriksen, J.; Bovee, K.; Bartholow, J. The Instream Flow Incremental Methodology: A Primer for IFIM, Biological Report 29; United States National Biological Service: Fort Collins, CO, USA, 1995.

17. United States Department of Agriculture. Stream Corridor Restoration: Principles, Processes, and Practices. In Proceedings of the Wetlands Engineering and River Restoration Conference 1998, Denver, CO, USA, 22-27 March 1998.

18. Rutherfurd, I.D.; Jerie, K.; Marsh, N. A Rehabilitation Manual for Australian Streams; Land and Water Resources Research and Development Corporation, Cooperative Research Centre for Catchment Hydrology, Department of Civil Engineering, Monash University: Clayton, Australia, 2000.

19. Koehn, J.D.; Brierley, G.J.; Cant, B.L.; Lucas, A.M. River Restoration Framework; Land and Water Australia: Canberra, Australia, 2001.

20. Wolters, H.A.; Platteeuw, M.; Schoor, M.M. Guidelines for Rehabilitation and Management of Floodplains Ecology and Safety Combined; NCR-Publication 09-2001; European INTERREG Rhine-Meuse Activities (IRMA) and Netherlands Centre for River Studies (NCR): Delft, The Netherlands, 2001.

21. Schueler, T.; Brown, K. Urban Subwatershed Restoration Manual No. 4, Urban Stream Repair Practices Version 1.0; United States Environmental Protection Agency: Washington, DC, USA, 2004.

22. Schueler, T. Urban Subwatershed Restoration Manual No. 1, An Integrated Framework to Restore Small Urban Watersheds Version 2.0; United States Environmental Protection Agency: Washington, DC, USA, 2005.

23. Schiff, R.; MacBroom, J.G.; Bonin, J.A. White Paper River Restoration and Fluvial Geomorphology; The New Hampshire Department of Environmental Services and The New Hampshire Department of Transportation: Concord, NH, USA, 2006.

24. Korea Institute of Civil Engineering and Building Technology. ECORIVER21 Technical Report; ECORIVER21; Korea Institute of Construction Technology, Ministry of Land, Transport and Maritime Affairs Environment Agency, Korea Institute of Construction \& Transportation Technology Evaluation and Planning: Goyang-si, Gyeonggi-do, Korea, 2010.

25. Korea Institute of Civil Engineering and Building Technology. Integrated Manual of Stream Restoration; ECORIVER21; Korea Institute of Construction Technology, Ministry of Land, Transport and Maritime Affairs Environment Agency, Korea Institute of Construction \& Transportation Technology Evaluation and Planning: Goyang-si, Gyeonggi-do, Korea, 2011.

26. Sousa-Santos, C.; Robalo, J.I.; Francisco, S.M.; Carrapato, C.; Cardoso, A.C.; Doadrio, I. Metapopulations in temporary streams-The role of drought-flood cycles in promoting high genetic diversity in a critically endangered freshwater fish and its consequences for the future. Mol. Phylogenet. Evol. 2014, 80, 281-296. [CrossRef] [PubMed]

27. Kauffman, J.B.; Beschta, R.L.; Otting, N.; Lytjen, D. An ecological perspective of riparian and stream restoration in the western United States. Fisheries 1997, 22, 12-24. [CrossRef]

28. National Research Council. Restoration of Aquatic Ecosystems: Science, Technology; Public Policy, National Academy Press: Washington, DC, USA, 1992.

29. Bradshaw, A.D. Underlying principles of restoration. Can. J. Fish. Aquat. Sci. 1996, 53, 3-9. [CrossRef]

30. Rosgen, D.L. A classification of natural rivers. Catena 1994, 22, 169-199. [CrossRef]

31. Rossman, L.A. Storm Water Management Model User's Manual; version 5.0; Water Supple and Water Resources Division National Risk Management Research Laboratory, United States Environmental Protection Agency: Cincinnati, OH, USA, 2010.

32. United States Army Corps of Engineers. HEC-RAS River Analysis System User's Manual, version 4.1; CPD-68; U.S. Army Corps of Engineers Hydrologic Engineering Center: Davis, CA, USA, 2010.

33. United States Environmental Protection Agency. DFLOW User's Manual; Risk Reduction Engineering Laboratory Office of Research and Development: Washington, DC, USA, 1990.

34. United States Geological Survey. PHABSIM for Windows, User Manual and Exercises; Midcontinent Ecological Science Center, US Geological Survey: Washington, DC, USA, 2001.

35. Peter, S.; Julia, B. River2D: Introduction to Depth Averaged Modeling and User's Manual; University of Alberta: Edmonton, AB, Canada, 2002.

36. Copeland, R.R. Application of Channel Stability Methods-Case Studies; TR-HL-94-11; Waterways Experiment Station, United States Army Corps of Engineers: Washington, DC, USA, 1994. 
37. United States Environmental Protection Agency. Technical Guidance Manual for Performing Wasteload Allocations. Book VI: Design Conditions-Chapter 1: Stream Design Flow for Steady-State Modeling; US EPA: Washington, DC, USA, 1986.

38. Radspinner, R.R.; Diplas, P.; Lightbody, A.F.; Sotiropoulos, F. River training and ecological enhancement potential using instream structures. J. Hydraul. Eng. 2010, 136, 967-980. [CrossRef]

(C) 2019 by the authors. Licensee MDPI, Basel, Switzerland. This article is an open access article distributed under the terms and conditions of the Creative Commons Attribution (CC BY) license (http:/ / creativecommons.org/licenses/by/4.0/). 